\title{
A Challenge to language learning directors
}

Arthur J. Gionet

North Texas State University

"After opening the box, I found some strange little gadgets and pieces of machinery that resemble somewhat cur clocks. Really, it is a book, a miraculous book, without pages, without any printed characters, a book indeed where the eyes are not useful at all: ears are all you need. When a client wishes to read, he simply activates this machine that contairs a great number of ccrnecting wires; then he sets the dial on the chapter he wishes to hear. and, at the same time, outcome the sounds of a musical instrument or the different sounds of speech directly from the mouth of a living person, that is, the sounds that the inhabitants of the moon use to communicate with one another."1

The above citation is amazing in its application to the subject at hand: the language laboratory-amazing because it was written over 350 years ago by the imaginative French author. Savinien de Cyrano de Bergerac. Richard Aldington. an early twentieth century translator of Cyrano's work, saw in the above paragraph the description of the gramophone. ${ }^{2}$

From Cyrano's prophetic description of recording devices. there are two points that could be applied to modern day: first, the "magic" that modern electronic machinery evokes. and. second, the creative imagination that is required to continue the needed research in the use of the language laboratory.

In his article, "Business and the Academic Humanist." Arnold Barach describes the accepted dichotomy of the business and the academic world, "The Ivory Tower has an image of pleasant security, womb-like refuge from the cold world outside ... It is a picture that lends itself readily to idealization and contrasts starkly with the image of the business world, which is seen as being overlayed with tension pressure, competition, and all the other classic ingredients of a bad case of ulcers." 3 To the faculty, the language laboratory director appears sometimes to be the business man, or rather the technician, that has encroached upon the academic field. The glassed-in booths, 
the master-control room, the maze of electronic equipment are dazzling and seem to separate him from his colleagues. Just as Barach refuses to accept the image of the professor in his Ivory Tower and of the business man in his pressure-filled and competitive world as a true reflection of reality, no gulf should be allowed to exist between the laboratory director and his teaching colleagues. Let us discard any assumption that there is a separation between the world of tape machines and that of learning the total concept of another man's culture; the language laboratory has a role to play at every level of language learning.

In the late fifties, when the audio-lingual method took a firm hold in our public schools and universities, and when the impetus of Sputnik aroused Congress to come to the aid of educators through the NDEA programs, foreign language teachers throughout the country thought they had found the "magic" key to foreign language learning and teaching. The language laboratory was going to be the "native" teacher. Professor Higgins describes the disillusionment that was to come, "When laboratories were first introduced, it was believed that if a student could listen to what he had said and compare it with what he was supposed to have said, then all problems in pronunciation would vanish overnight. But this never occurred."4 Fantastic claims were never substantiated. Too much was expected of the impersonal language laboratory. In my opinion, the use of the language laboratory can never fully reach its potential without the active involvement of the whole faculty in cooperation with the laboratory director and his associates. "The machines alone will do nothing without properly constructed materials."'s

The present looks gloomy. The teachers are disenchanted with the current teaching techniques; the enrollment in foreign language courses is dropping drastically across the nation; those who pursue language studies seem to be disinterested in their work and find their laboratory assignments uninteresting, uninspiring, and feel that the whole language program is "irrelevant" to modern problems. 6 Grittner and LaLeike tell us that in individualized instruction programs "the central console of the typical language laboratory is a dubious investment ... and the audioactive dial-access system is also of questionable value because it does not allow the student to stop and start the program or.ce he has selected it."7 Many believe with professor Valette "that the laboratory as it has been generally utilized over the past several years has not contributed significantly to improving the students' audio-lingual skills." 8 The challenge to foreign language teachers and specifically to language learning directors is to revive, ressuscitate, to give an all-powerful vitamin pill to our language programs; and I believe that the laboratory has a very important role to play in 


\section{Challenge}

this revival. It is up to our profession to pick up the challenge as defined by professor Valette, "the 'hardware' of the laboratory has undergone continual refinement over the past ten years, but the 'software' has hardly changed. The challenge of the next decade will be the development of imaginative and more effective tape programs."

Textbook publishers seem to have taken the lead. Texts are getting away from "Where is the pencil? What color is the chalk?" and offer topics of discussion that would seem to appear to the maturity level of our students. Nouveau Visage du monde francais best exemplifies the new trend in textbooks. Topics such as "Twentieth century shopping in France, The 'Big Mac' offensive in Paris" are discussed. If only new, simple imaginative laboratory exercises could be devised to support the new materials, and these reinforced with films and slides, and the genuine support of laboratory supervisors and teachers, perhaps a renewal of interest can be aroused in foreign languages.

The objection that is most likely to arise from the offering of such materials will be that they are not "literary," that they replace the great works found in literature. It is true that the "new" materials are not necessarily literary; but the realities of the world are here with us today. "Our courses must affect our students' lives 'now'."10 Is there really such a chasm between the daily world and the literature of the present? The "new" materials are an integral part of modern culture, are they not? Professor Lippman warns not to turn our departments into trade schools, yet she advocates a variety of offerings at all levels." ${ }^{11}$ Foreign language study is no longer limited to the intellectual elite; 12 it has a "liberal arts" role in all learning endeavors. Furthermore, if the "new" materials attract the masses that our colleges and universities are trying to educate, do we not have a better chance to get them interested in the world of literature; do we not have a duty to meet their needs which may not always be of a literary nature? I see in the new trend a challenge, another chance to "modernize" our language programs.

Other areas are in need of research. It was not accidental that the language laboratory was first called a "laboratory" since it has a two-fold purpose: "it is both a research centre and a training centre for specialists." 13 Up to now the laboratory has been mostly utilized as a laboratory. A group of French educators remind us that "The language laboratory does open the door to one little known field of work, which calls for the co-operation of linguists, psychologists and educationalists, i.e. the observation of the student in the actual process of learning."14 Professor Dodson identified further the area of research that is needed, "A search must be made for additional ideas, discoveries, inventions, aids and equipment from other fields of human 
activity so as to heighten the degree of efficiency if the system (and to remove) from the learning process the drudgery and obstacles that are now considered to be unavoidable and even necessary ingredients in education."1s Perhaps this is the time to coordinate the individual efforts of the psychologist, the linguist, the classroom language teacher like those of the business man and the academic world who met in Washington in December of 1974 to analyze their relationships. ${ }^{16}$ "If the (laboratory) maintains this double orientation, i.e. both a research centre and a training centre for specialists, it will stimulate new educational thinking and experimentation."17

Everyone knows that the language laboratory is a teaching tool and not a mechanical teacher; and yet, such demands are still placed upon its services. Grittner and LaLeike think that, "Ideally a language laboratory designed for individualization would consist of learning stations that allow for totally autonomous performance."18 In order to give the greatest help and encouragement to our students, laboratory sessions have to be supervised by "live" assistants. Professor Mueller says, "The laboratory is at its weakest point when it is expected to perform the miracle of teaching the listening and speaking skills alone without the coordination and the integration of classroom activities and materials, when used only for enrichment and peripheral activities."19

Many instructors consider the work done in the laboratory as extra-curricular, an optional assignment and not even a worthwhile learning experience. Grades, which are a significant motivation for many students, seldom indicate a proportionate consideration for this kind of activity. Comprehension tests admittedly are given but in the final analysis the stress is placed on the grammatical structure of the language and/or the students' ability to read and to understand the written word. But when and where does the testing of oral proficiency occur? The same problems face French educators teaching their students English: "The present system of examination does nothing to encourage the student in his interest in the spoken language. None of the oral examinations which he has to undergo has any real value as a test of his oral comprehension and expression ... Only a new system of examinations involving an independent and objective assessment of the quality of spontaneous expression in the foreign language will ensure patient and sustained work being done on the spoken language."20 Charles Dodson complains about the same situation in England, "It is most important that the pupils' oral proficiency is also tested, especially as this is the basic skill on which everything else is built."21 It is specifically in this area that the knowledge, the skill and the experience of the language laboratory director can serve the profession immeasurably. What is needed are 


\section{Challenge}

new, practical ways of testing oral proficiency, and the distribution of proven techniques to teachers through national publications.

The challenges of the ' 70 's that face the language learning director and the teacher encompass research in innovative testing devices, new approaches in humanizing the laboratory, dialogues between the langu. age teacher and his academic colleagues, and the area of public relations. Even though the responsibility of the image of the university in the community, and particularly the image of the foreign language department, is shared with the adminstration and the faculty, the language laboratory director could very well take the lead in this direction. Individualized foreign language instruction in recent years has attracted many proponents, and propesed courses are just beginning to appear on the horizon. While preparing this paper for NALLD members, I came across an article in the March 1975 Bulletin of the Association of Departments of Foreign Languages entitlcl. "A Proposal to Develop Individualized Materials for Limited-Obicctive Career Spanish Programs," an article that clearly identifies the services a Foreign Language Department could offer to its students and to the members of the community. Professor Pilkenton of Mesa College, Grand Junction, Colorado, proposes among others the following course options, "Medical Spanish (for nursing and pre-medicine majors), Spanish for Child Care, . . . Spanish for Prospective Law Enforcement Officers, ... Spanish for Prospective Stewardesses, . . . Spanish Commercial Correspondence." To this list could be added a mini-course aimed specifically to meet the needs of the American tourists in Europe: customs, the rate exchange of morey medical scrvices. what to do if one gets lost or loses his passport. etc. Because of his highly technical knowledge, the laboratory director could also lead the faculty in the area of broadcasting foreign culture programs, weekly news in the language, special occasion programs, etc. The department of foreign languages and literatures at North Texas State University has been offering since January 1975 a weekly program on certain cultural aspects about France and French speakirg countries. Spanish and Latin America, Germany, Russia and Ancient Rome. All these functions play an important role in the image of the foreign language department in the community.

The thought that the audio-lingual method was the panacea to all language learning and teaching problems has passed. The language laboratory as the "live" native speaker that would teach our students by itself and create "real" Frenchmen, Spaniards or Germans has also passed. The hard realities of the seventies: the drop of enrollment, the indifference of the students, the uncertainties of the present, are facing all language teachers. The challenges are formidable. Yet, I am sure that the Cyrano's of modern times will come forward and 
meet the demands of today. I share Professor Higgins' hope, "With imagination the language laboratory can be harnessed. . . to assist in the teaching of form and meaning in context, to give practical language skills to anyone with the will to learn and through these skills to provide a fuller life and understanding. At its best, it is a very democratic machine."22

\section{FOOTNOTES}

'Savinien de Cyrano de Bergerac, Histoire Comique des Etats et Empires de la Lune et du Soleil, nouvel e edition, par P. L. Jacob, Galic, Paris, 1962, p. 190.

${ }^{2}$ Cyrano de Bergerac, Voyages to the Moon and Sun, translated by Richard Aldington, Routledge and Sons Ltd., London, 1900?, p. 146.

3Arnold Barach, "Business and the Academic Humanist" in Humanities in the South, No. 41, Spring 1975, Spartanburg, S.C., p. 1.

$4 \mathrm{~J}$. J. Higgins, $A$ Guide to Language Laboratory Material Writing, Universitetsforlaget, Oslo, 1969, p. 13.

sHiggins, p. 9.

6See my article, "Current Foreign Language Methods" in French Review, Vol. XLVIII, No. ${ }^{1}$ Oct. 1974, pp. 17-24.

7Frank M. Grittner and Fred H. LaLeike, Individualized Foreign Language Instruction, National Textbook Co., Skokie, Ill., 1973, p. 59.

sRebecca M. Valette, "Some Conclusions to be Drawn from the Pennsylvania Study" in NALLD Newsletter, Vol. III, No. 3, p. 19.

9Valette, p. 19.

10Jane N. Lippman, "Rationale for Language Study" in The Challenge of Communication, Gilbert A. Jarvis Editor, National Textbook Company, Skokie, Ill., 1974, p. 50.

"Lippman, p. 47.

12Lippman, p. 51.

13Yves Chalon, C. Bouillon, H. Holec, M. Kuhn and C. Zoppis, The Language Laboratory in Higher Education: An Experiment, Aidela, Strasbourg, 1968, p. 7. ${ }^{14}$ Chalon, p. 8.

15Charles J. Dodson, Language Teaching and the Bilingual Method, Pitman Publishing, Bath, England, 1972, p. 3.

16Barach, pp. 1-4.

${ }^{17}$ Chalon, p. 7.

18Grittner, p. 59.

19Theodore $\mathrm{H}$. Mueller, "Correlating the Language Laboratory with the Textbook", in Structural Drill and the Language Laboratory, Francis W. Gravit and Albert Valdman editors, Indiana University, Bloomington, Indiana, 1963, p. 83.

${ }^{20}$ Chalon, p. 9.

2'Dodson, p. 145.

22Higgins, p. 171. 